\title{
Isolation and Characterization of an Abnormal High Density Lipoprotein in Tangier Disease
}

\author{
Gerd Assmann, Peter N. Herbert, Donald S. Fredrickson, and Trudy Forte \\ From the Abteilung für Klinische Chemie und Zentrallaboratorium der Universitätskliniken \\ Köln, 5 Köln, West Germany; the Molecular Disease Branch, National Heart and Lung \\ Institute, National Institutes of Health, Bethesda, Maryland 20014; and the \\ Donner Laboratory, University of California, Berkeley, California 94720
}

\begin{abstract}
A B S T R A C T The nature of the high density lipoproteins has been investigated in five patients homozygous for Tangier disease (familial high density lipoprotein deficiency). It has been established that Tangier high density lipoproteins, as isolated by ultracentrifugation, are morphologically heterogenous and contain several proteins (Apo B, albumin, and Apo A-II). An abnormal lipoprotein has been isolated from the $d=1.063$ $1.21 \mathrm{~g} / \mathrm{ml}$ ultracentrifugal fraction by agarose-column chromatography which contains apoprotein A-II as the sole protein constituent. In negative-stain electron microscopy, these lipoproteins appeared as spherical particles 55-75 $\AA$ in diameter. By a variety of criteria (immunochemical, polyacrylamide electrophoresis, amino acid composition, and fluorescence measurements), apoprotein A-I the major apoprotein of normal high density lipoproteins and the $\mathrm{C}$ apoproteins were absent from this lipoprotein. As demonstrated by ${ }^{125}$ I very low density lipoprotein incubation experiments with Tangier plasma, $C$ apoproteins did not associate with lipoproteins of $d$ $=1.063-1.21 \mathrm{~g} / \mathrm{ml}$. Tangier apoprotein A-II, isolated to homogeneity by delipidation of the apoprotein A-II-containing lipoprotein or Sephadex G-200 guanidine-HCl chromatography of the $d=1.063-1.21$ $\mathrm{g} / \mathrm{ml}$ fraction, was indistinguishable from control apoprotein A-II with respect to amino acid composition and migration of tryptic peptides in urea-polyacrylamide electrophoresis. The ability of Tangier apoprotein A-II to bind phospholipid was demonstrated by in vitro reconstitution experiments and morphological and chemical analysis of lipid-protein complexes.

It is concluded that normal high density lipoproteins, as defined by polypeptide composition and
\end{abstract}

Received for publication 17 December 1976 and in revised form 14 February 1977. morphological appearance, are absent from Tangier plasma and that as a consequence, the impairment of $\mathrm{C}$ apoprotein metabolism contributes to the hypertriglyceridemia and fasting chylomicronemia observed in these patients.

\section{INTRODUCTION}

Tangier disease is a rare disorder of plasma lipid transport characterized by the near absence of plasma high density lipoproteins (HDL). ${ }^{1}$ Clinical manifestations are related to the storage of cholesteryl esters in reticuloendothelial tissues and the occurrence of sensory and motor neuropathies (1). Evidence has been provided that patients with Tangier disease have small amounts of HDL in their plasma which is not identical to the normal lipoproteins of this density class $(2,3)$. There is an absolute decrease in the amount of Apo A-I and Apo A-II, the major apoproteins of HDL, in Tangier plasma and the Apo A-I appeared disproportionately decreased with respect to Apo A-II $(2,3)$. Such a profound change in apoprotein composition undoubtedly alters the physical and metabolic properties of Tangier HDL, but the minute quantities of HDL recoverable from Tangier plasma have generally frustrated attempts to define these changes.

In the present study, we have further examined the chemical and structural features of Tangier HDL. The lipoproteins in this density class proved to be extremely pleomorphic and a lipoprotein form has been identified and characterized which contains only the A-II apoprotein.

\footnotetext{
${ }^{1}$ Abbreviations used in this paper: HDL, high density lipoproteins; $\mathrm{HDL}_{\mathrm{TG}}$, agarose fraction III from Tangier high density lipoproteins; LCAT, lecithin-cholesterol acyltransferase; SPM, sphingomyelin; VLDL, very low density lipoproteins.
} 


\section{METHODS}

Patients. Five patients homozygous for Tangier disease (C.N., T.L., P.L., E.G., and J.S.) were donors of the Tangier plasma. Their clinical manifestations have been described in detail in previous reports from our laboratories $(2,4-8)$.

Isolation of lipoproteins. Plasma was collected in $0.01 \%$ EDTA by plasmaphěresis of patients and normal subjects who had fasted overnight. The background density of the plasma was raised with solid $\mathrm{KBr}$ to a calculated density of $1.063 \mathrm{~g} / \mathrm{ml}$. The plasma was then centrifuged in a $60 \mathrm{Ti}$ rotor in a Beckman L2 65 B instrument (Beckman Instruments, Inc., Spinco Div., Palo Alto, Calif.) at 60,000 rpm for $16 \mathrm{~h}\left(2.44 \times 10^{8} \mathrm{~g}\right.$-min $)$. The tubes were sliced $30 \mathrm{~mm}$ below the tops and the infranate was adjusted to 1.210 $\mathrm{g} / \mathrm{ml}$ with additional $\mathrm{KBr}$ and then recentrifuged at 60,000 $\mathrm{rpm}$ in a $60 \mathrm{Ti}$ rotor for $48 \mathrm{~h}\left(7.32 \times 10^{8} \mathrm{~g}-\mathrm{min}\right)$. The 1.21$\mathrm{g} / \mathrm{ml}$ supernatant fraction, obtained by slicing the tubes $20 \mathrm{~mm}$ below the tops, was readjusted to $d=1.21$ and centrifuged at $40,000 \mathrm{rpm}$ in a 40 rotor for $48 \mathrm{~h}\left(3.04 \times 10^{8} \mathrm{~g}\right.$-min). Appropriate blanks of identical salt composition and density were included to determine the salt density of supernatant and infranatant fractions after each centrifugation. The centrifuged lipoproteins from the $1.063-1.21-\mathrm{g} / \mathrm{ml}$ range (HDL) were used for further fractionation by agarose-column chromatography.

Gel chromatography. HDL were dialyzed against 100 vol of $0.05 \mathrm{M} \mathrm{NH}_{4} \mathrm{HCO}_{3}$ buffer, $\mathrm{pH} \mathrm{8}$, containing $0.01 \%$ EDTA, and fractionated on a column of Biogel A, $1.5 \mathrm{M}$, 100-200 mesh $(2 \times 90 \mathrm{~cm})$ (Bio-Rad Laboratories, Richmond Calif.) equilibrated in the same buffer. The eluate $(10 \mathrm{ml} / \mathrm{h})$ was monitored by absorbance at $230 \mathrm{~nm}$. Appropriate column fractions were pooled and concentrated by diaflow ultrafiltration to a final volume of $0.5-1.5 \mathrm{ml}$.

Analysis of column fractions. The lipoprotein patterns of agarose-column fractions were evaluated by polyacrylamide electrophoresis (separating gel: $3 \%$ polyacrylamide, $0.25 \%$ $\mathbf{N}, N^{\prime}$-methylenebisacrylamide) (9). In this electrophoretic system, HDL migrate rapidly as a sharp single band (ca. 5 $\mathrm{cm}$ from the stacking-separating gel interface) and is well separated from very low density lipoproteins (VLDL) and low density lipoproteins. Column fractions, containing material with HDL mobility, were combined and analyzed for their apoprotein composition by analytical polyacrylamide gel electrophoresis in $8 \mathrm{M}$ urea, pH $9.4(10)$, or $1 \%$ sodium lauryl sulfate at pH 8.2 (11). HDL apoproteins used as reference material in these studies were isolated by previously described procedures (12).

Incubation experiments. To investigate the in vitro ex-

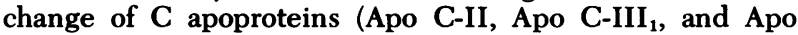
C-III ${ }_{2}$ ) from the VLDL to the HDL density range, ${ }^{125} \mathrm{I}-$ VLDL was incubated with normal and Tangier plasma. VLDL isolated from a normolipidemic volunteer by ultracentrifugation at $d<1.006$ were labeled with ${ }^{125} \mathrm{I}$ according to the McFarlane technique (13) as modified by Bilheimer et al. (14). Assuming a mol wt of 300,000 for the entire VLDL apoprotein, the atom/mole ratio of iodine to protein was 0.5 . $1 \mathrm{mg}$ of ${ }^{125} \mathrm{I}$-labeled VLDL protein was added to $50 \mathrm{ml}$ of fresh plasma obtained from Tangier patients (E.G. and J.S.) or fresh normolipidemic control plasma. The plasma was incubated for $1 \mathrm{~h}$ at $37^{\circ} \mathrm{C}$ and the lipoproteins were then isolated by sequential ultracentrifugation at $4^{\circ} \mathrm{C}$. Radioactivity of the individual density fractions was measured after dialysis against $100 \mathrm{vol}$ of $0.9 \% \mathrm{NaCl}$ (Packard auto-gamma scintillation spectrometer, model 5230, Packard Instrument Co., Inc., Downers Grove, Ill.). Individual lipoproteins were delipidated with chloroform-methanol, and the radioactivity of the apoproteins was determined after urea-polyacrylamide electrophoresis in 5-mm gel slices. The chloroform-methanol phase was also assayed for radioactive content.

Reassembly experiments. Apoprotein A-II, isolated from one of the patients homozygous for Tangier disease (C.N.) and control patients, was tested for its ability to form a protein-lipid complex with sphingomyelin (SPM). A ${ }^{3} \mathrm{H}$ label was chemically introduced into the choline moiety of SPM (beef brain, Sigma Chemical Co., St. Louis, Mo.) (15). $\left[\mathrm{N}-\mathrm{C}^{3} \mathrm{H}_{3}\right.$-choline]SPM (sp act $2.8 \times 10^{5} \mathrm{cpm} / \mu \mathrm{mol}$ ) was purified by silica-gel chromatography and subsequently used as sonicated dispersion for recombination with Apo A-II as previously described (16). Lipid-protein complexes were isolated by sequential ultracentrifugation between $d$ $=1.063-1.21 \mathrm{~g} / \mathrm{ml}$ and subsequent agarose-gel chromatography (16). Ultracentrifugal and column fractions were analyzed for phospholipid by determination of radioactivity, and for protein by the method of Lowry et al. (17). Column fractions containing the Apo A-II- $\left[{ }^{3} \mathrm{H}\right] \mathrm{SPM}$ complex were pooled and concentrated by diaflow filtration to a protein concentration of $500 \mu \mathrm{g} / \mathrm{ml}$.

Enzymatic digestions. Apo A-II from Tangier and control samples was enzymatically digested with trypsin (L[1tosylamido-2-phenyl]ethyl chlormethyl ketone treated, Worthington Biochemical Corp., Freehold, N. J.) at $37^{\circ} \mathrm{C}$ for $45 \mathrm{~min}$ in $0.1 \mathrm{M} \mathrm{NH}_{4} \mathrm{HCO}_{3}$ buffer, $\mathrm{pH} \mathrm{8}$, using an enzymeprotein weight ratio of $1: 30$.

Tryptic peptides were analyzed by urea-polyacrylamide gel electrophoresis and thin-layer chromatography $(100-\mu \mathrm{m}$ thick plates of cellulose F [Brinkmann Instruments, Inc., Westbury, N. Y. developed with butanol-pyridine-acetic acidwater 30:20:6:24] [18]). The plates were sprayed with $1.25 \%$ ninhydrin in acetone-water (16:1) containing $0.125 \%$ cadmium acetate and developed at $110^{\circ} \mathrm{C}$ for $10 \mathrm{~min}$.

Spectroscopic methods. Samples analyzed by circular dichroism spectroscopy were dialyzed against $100 \mathrm{vol}$ of $0.05 \mathrm{M}$ sodium phosphate buffer, $\mathrm{pH}$ 8. Spectra were recorded using a Cary 60 spectropolarimeter (Cary Instruments, Fairfield, N. J.) equipped with Pockels cell and standardized with potassium dichromate. The spectra reported are the mean of four repetitive analyses of each preparation. The signal-to-noise ratio was always greater than 10:1. The mean residue ellipticity in units of degree/square centimeter per decimole was calculated from $\boldsymbol{\theta}=(\mathrm{MRW})$ $(\theta) \lambda \% 10 \mathrm{l} c$ where $\left(\Theta \lambda^{\circ}\right.$ is the observed ellipticity in degrees at wavelength; 1 , the optical path in centimeters; $c$, the concentration in grams per milliliter; and MRW, the mean residue weight calculated from amino-acid analyses (Apo A-II: 117). The degree of alpha-helical structure in the individual samples was estimated at $222 \mathrm{~nm}$ assuming a value of 29,000 for a completely helical protein and little or no residues in $\beta$-structure (19). Fluorescence measurements were made in the Turner model 210 corrected spectrofluorometer (G. K. Turner Associates, Palo Alto, Calif.) equipped with thermostated cell holders (20).

Electron microscopy. Lipoprotein fractions were dialyzed against $1 \%$ ammonium acetate buffer, $\mathrm{pH} 7.4$, containing $5 \mathrm{mg} / \mathrm{l}$ EDTA. Fractions were diluted and mixed with an equal volume of $2 \%$ sodium phosphotungstate, $\mathrm{pH}$ 7.4 , to a final concentration of $50-250 \mu \mathrm{g} / \mathrm{ml}$. A droplet was placed on a Formvar/carbon-coated grid, excess fluid was removed with filter paper, and the negatively stained preparation was then examined in an electron microscope. Lipoprotein size distribution was determined from measurements of 200-800 particles.

Other methods. Proteins were hydrolyzed in constant boiling $\mathrm{HCl}$ containing 2-mercaptoethanol (1:2,000, vol/vol) in clamped evacuated dessicators that had been repeatedly 


\section{TANGIER \\ $d=1.063-1.21$}

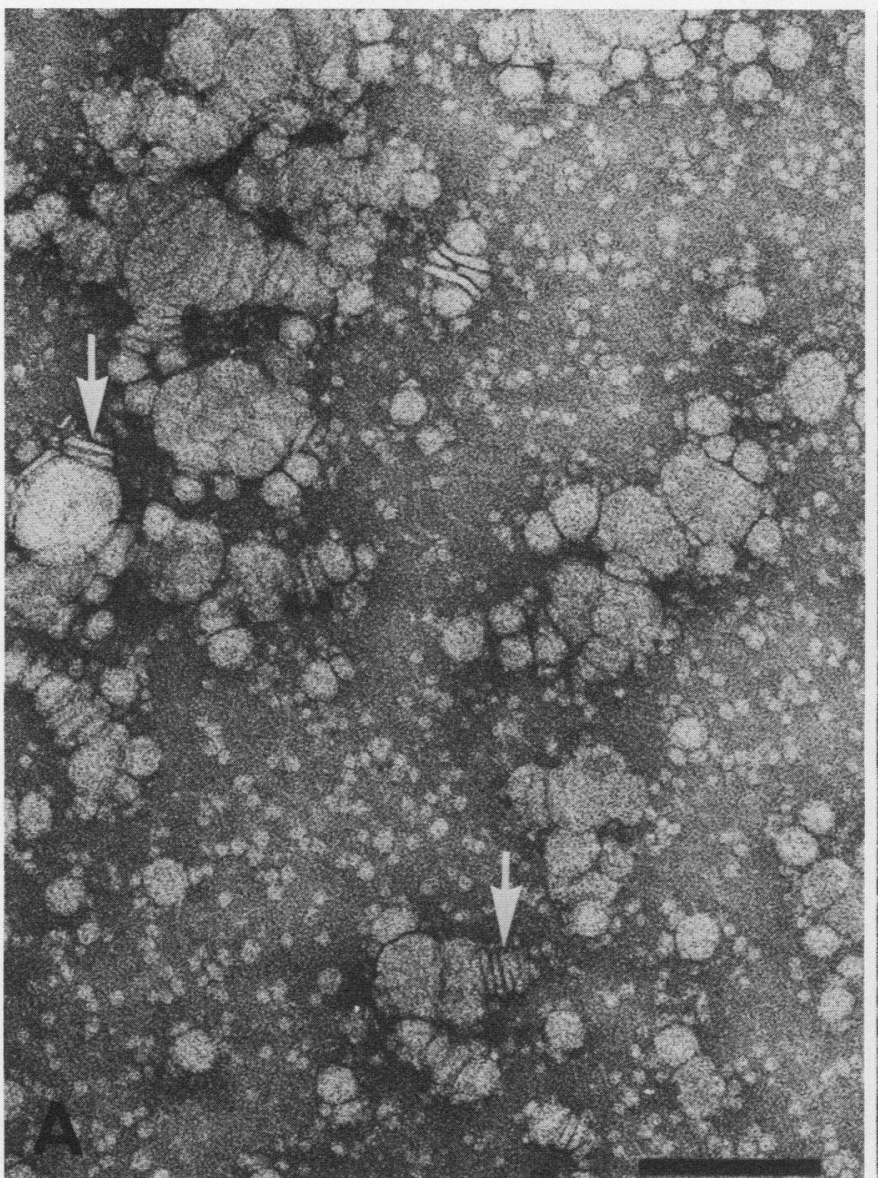

NORMAL
$d=1.063-1.21$

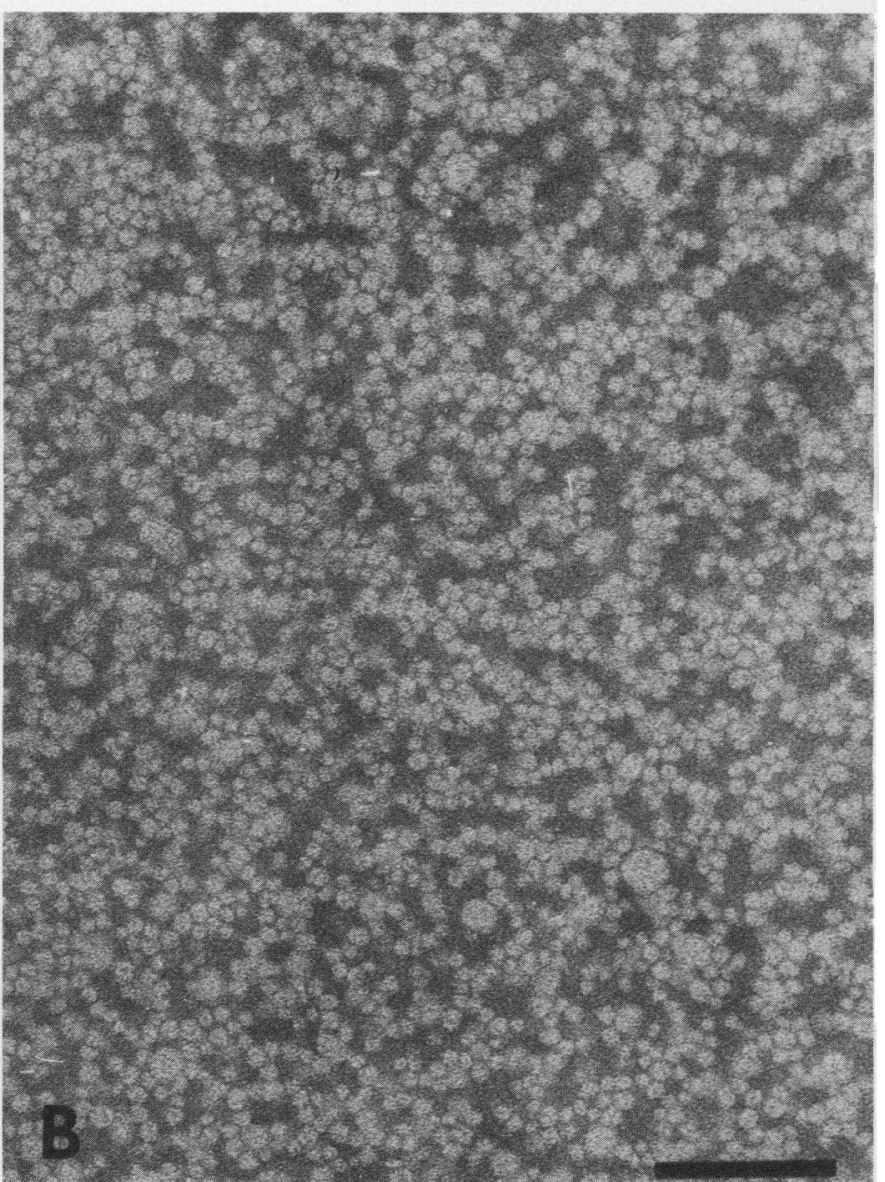

FigURE 1 Negative stains of HDL $(d=1.063-1.21)$ from Tangier (C.N.) and normal plasma $(\times 180,000)$. The bar markers represent $1,000 \AA$. (A) Tangier HDL isolated by ultracentrifugation and concentrated by ultrafiltration appear to contain several populations of particles: the diameter of the smallest particles ranges between 55 and $75 \AA$; a second group of extremely large, often amorphous, structures is also present (these particles of irregular size appear to increase on diets high in fat); a third group consists of discoidal particles with a tendency to form stacks (see arrows). (B) Normal plasma HDL appearing homogeneous in size (90-150 $\AA$ ).

flushed with nitrogen (21). Amino acid analyses were performed on a Beckman model 121 amino acid analyzer (Beckman Instruments, Inc., Fullerton, Calif.) by the method of Moore et al. (22), using the "four hour hydrolyzate system" (23). No correction was made for amino acid degradation or incomplete protein hydrolysis.

Lipoproteins were delipidated using a chloroform: methanol, 2:1, solvent system (18). Lipid phosphorus was assayed with the malachite green reagent $(24,25)$ and phospholipid was estimated as the product of lipid phosphorus $\times 25$. Individual phospholipids were separated and identified by thin-layer chromatography using a solvent system of chloroform:methanol:water, 65:25:4. Free cholesterol and cholesteryl esters were separated by thin-layer chromatography (petroleum ether:ethyl ether:acetic acid, 70:30:1), scraped off the plates, and quantitated by the Zak et al. procedure (26).
Immunoelectrophoresis and double-diffusion were performed in $1 \%$ agarose buffered with $0.1 \mathrm{M}$ sodium barbital, $\mathrm{pH}$ 8.0. All antisera employed were specific for one apolipoprotein.

\section{RESULTS}

Characterization of Tangier HDL. The 1.063-1.21$\mathrm{g} / \mathrm{ml}$ ultracentrifugal fractions from the plasma of controls and three patients with Tangier disease were examined by an electron microscope. Control preparations were homogeneous, containing spherical particles of 90-150 $\AA$ diameter (Fig. 1). In contrast, large spherical particles, disk-like structures, and small 


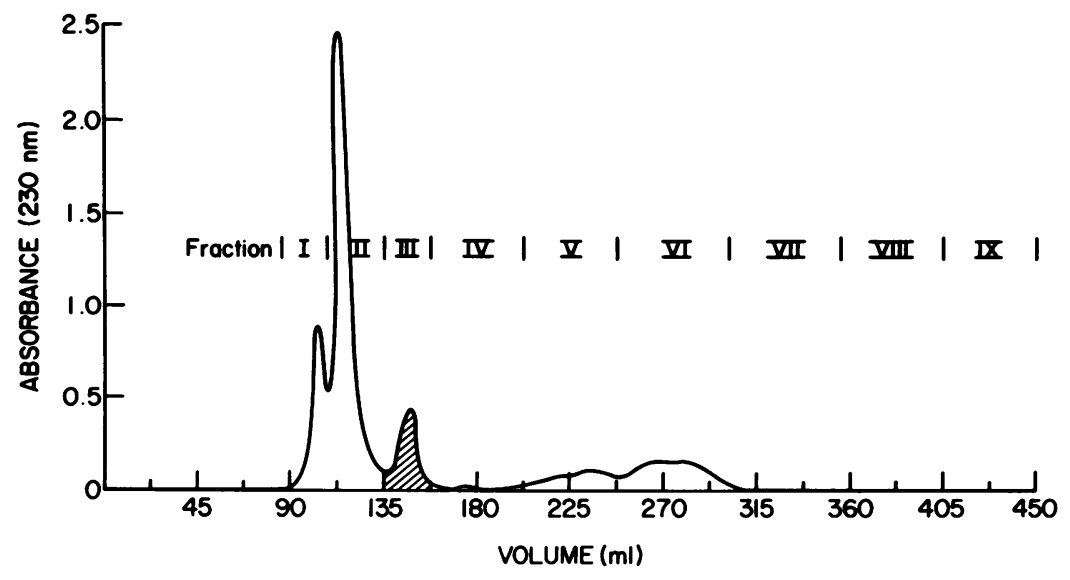

FIGURE 2 Agarose chromatography of Tangier HDL. Tangier HDL (P.L.) was isolated from $250 \mathrm{ml}$ of plasma by ultracentrifugation at $d=1.063-1.21 \mathrm{~g} / \mathrm{ml}$ and applied to a column of Biogel A, 1.5 M, 100-200 mesh, equilibrated in $10 \mathrm{mM} \mathrm{NH}_{4} \mathrm{HCO}_{3}$ buffer, pH 8.8, $0.01 \%$ EDTA (void volume $\left[\mathrm{V}_{\mathrm{o}}\right]=95 \mathrm{ml}$, salt volume $\left[\mathrm{V}_{\mathrm{s}}\right]=400 \mathrm{ml}$ ). As demonstrated by electron microscopy (not shown), fraction I contains primarily 165-230- $\AA$ particles, but also present were large, amorphous structures; fraction II consists of particles 170-200 $\AA$ in size; immunochemically, fractions I and II contain Apo B and no A apoproteins. Fraction III (shaded) contains spherical particles with 55-75 $\AA$ diameter and Apo A-II antigenicity. The latter fractions (IV, etc.) did not contain enough lipoprotein concentration to yield electron microscopy information. Immunochemically, fractions V and VI contained albumin.

spherical particles were present in the Tangier HDL (Fig. 1).

Tangier HDL eluted in three major and several minor peaks from an $8 \%$ agarose column (Fig. 2). Fractions I and II, emerging at or near the column void volumn, contained particles with diameters of $>200 \AA$. The material in these fractions was either retained in the stacking gel or had low $(\beta)$ mobility when examined by electrophoresis in $3 \%$ polyacrylamide (Fig. 3). Fractions IV-VI were inconsistently observed and, although occasionally generating bands on electrophoresis (Fig. 3), contained no structural elements identifiable by electron microscopy. These fractions were not further investigated. Immunochemically, none of these fractions contained Apo A-I or Apo A-II antigenicity.

Fraction III, which upon rechromatography eluted in the same position from the agarose column, contained mostly spherical particles of about $60 \AA$ diameter (Fig. 4) with alpha mobility in polyacrylamide electrophoresis (Fig. 3). These alpha-migrating lipoproteins were reproducibly isolated from the HDL of the five Tangier patients and were the subject of detailed analysis.

The protein composition of the agarose fraction III was qualitatively assessed by electrophoresis in $10 \%$ acrylamide gels containing $0.1 \%$ sodium lauryl sulfate. The major HDL apoproteins, Apo A-I and Apo A-II, have characteristic mobilities and the width and intensity of the bands in control HDL reflects the $3: 1$, Apo A-I:Apo A-II, weight ratio (Fig. 5). Only Apo
A-II was identified when the agarose column fraction III, without organic solvent delipidation, was similarly

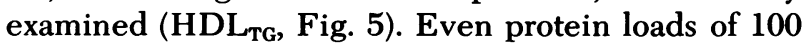
$\mu \mathrm{g}$ did not reveal the presence of Apo A-I, or other apoproteins, although with this technique a distinct Apo A-I band can be visualized in $5 \mu \mathrm{g}$ of normal Apo HDL. The absence of both Apo A-I and C apoproteins was also confirmed by electrophoresis in urea containing polyacrylamide gels.
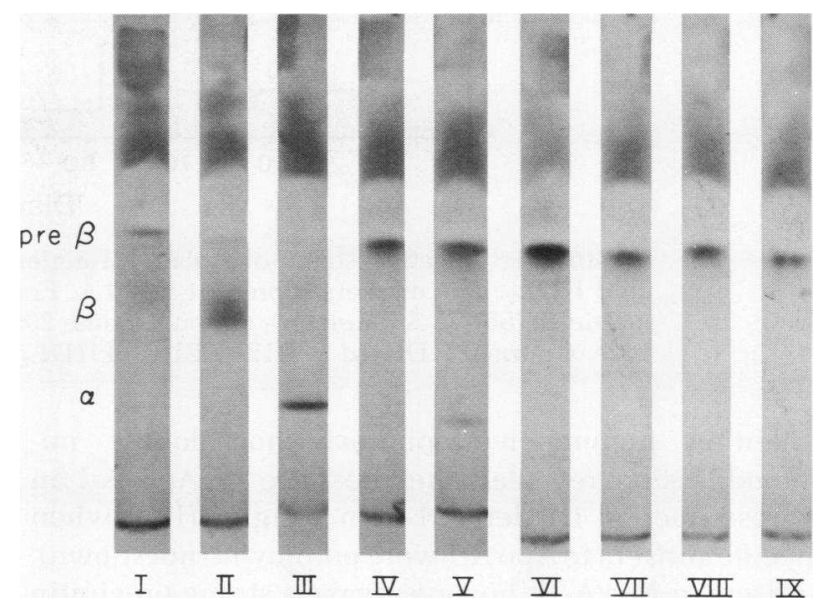

FIGURE 3 Polaroid photograph of polyacrylamide gel lipoprotein patterns of fractions I-IX (Fig. 2). Fractions I and II were retained in the stacking gel or had low $(\beta)$ mobility. Fraction III contained only lipoproteins with alpha mobility. Sudan black B was added to the loading gel to prestain the lipoprotein fractions. 

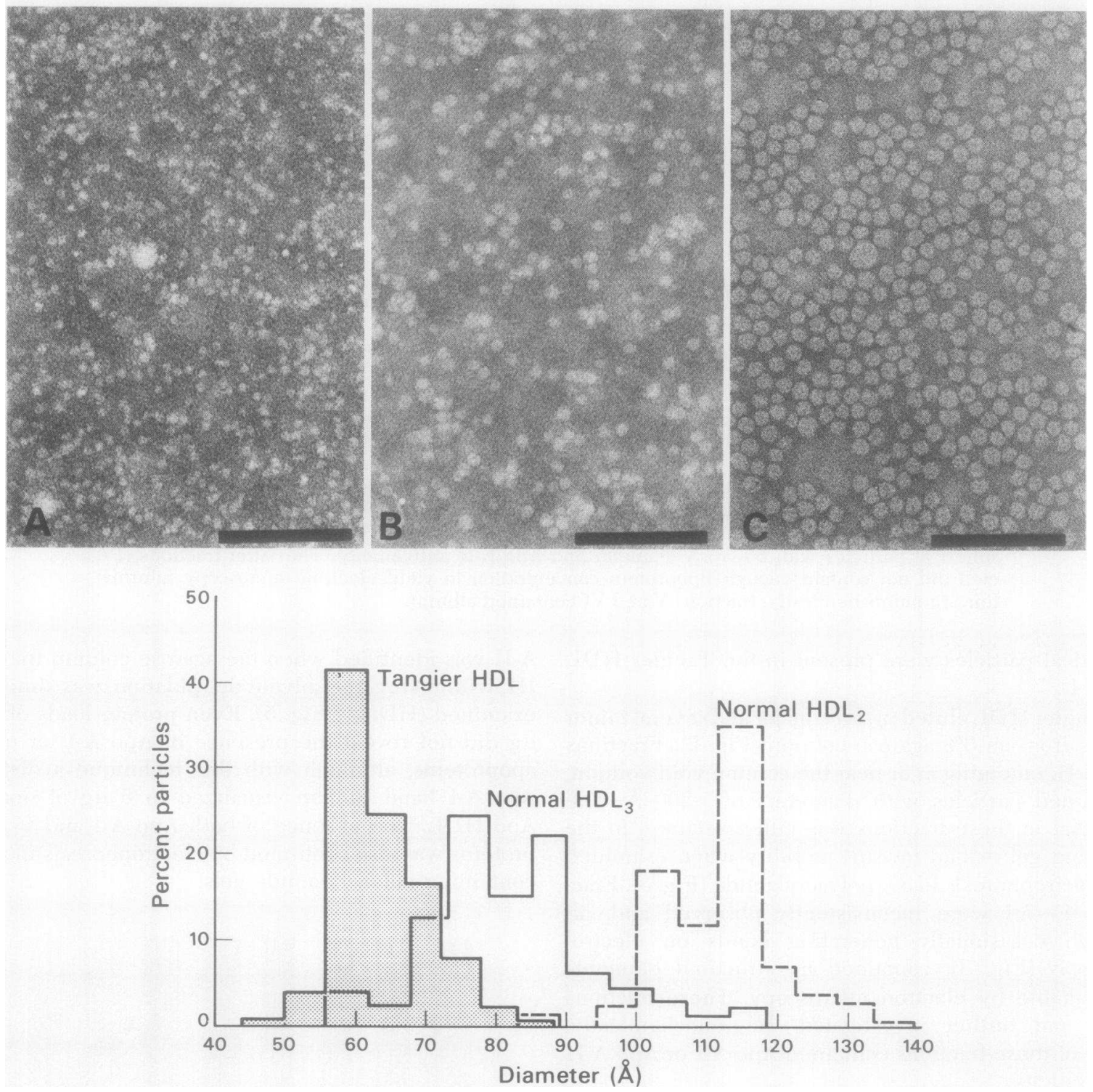

FIGURE 4 Negative stains of isolated Tangier HDL (agarose fraction III) and normal $\mathrm{HDL}_{3}$ and $\mathrm{HDL}_{2}$. The markers represent $1,000 \AA$. Fraction III (Figs. 2, 3) contained mostly spherical particles (55-75 $\AA$ diameter), although some $200-\AA$ size particles were still present. The average size of normal $\mathrm{HDL}_{3}(d=1.12-1.21)$ and $\mathrm{HDL}_{2}(d=1.063-1.12)$ is shown in the lower diagram.

Neither immunoelectrophoresis nor double immunodiffusion revealed the presence of Apo A-I in agarose fraction III derived from Tangier HDL when specific antisera to Apo A-I were employed (not shown). Antisera to Apo A-II, however, gave a strong precipitin line when tested against Tangier HDL or agarose fraction III (3). In two of the Tangier patients (E.G., J.S.), the absence of Apo A-I from Tangier HDL could also be demonstrated by specific radioimmunoassay (3). The absolute amount of Apo A-II contained in the
Tangier HDL ultracentrifugal fraction as assessed by radioimmunoassay (3) (1.1 mg/dl, patient J.S.) was comparable to the amount of Apo A-II recovered in agarose fraction III (0.95 mg/dl). In four preparations (J.S., E.G.), the amount of Apo A-II recovered in agarose fraction III varied from 0.8 to $1.35 \mathrm{mg} / \mathrm{dl}$. The finding that Apo A-II antigenicity is present in regular alphaelectrophoretic position when fresh Tangier serum is monitored by double immunoelectrophoresis argues against an artifactual in vitro production of the Apo 


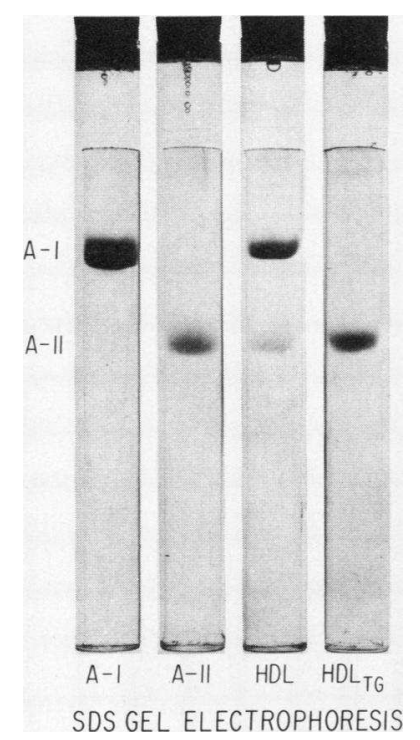

FIGURE 5 SDS polyacrylamide disc-gel electrophoresis of control Apo A-I, control Apo A-II, control HDL, and HDL (Figs. 2, 3).

A-II-containing lipoprotein as isolated by ultracentrifugation and agarose-column chromatography.

Apo A-II contains tyrosine but is the only known apolipoprotein with no tryptophan. The fluorescence spectrum of the Tangier Apo A-II particle $\left(\mathrm{HDL}_{\mathrm{TG}}\right.$, Fig. 6) excluded a significant content of any tryptophan-containing protein. The emission peak at 305 $\mathrm{nm}$ and the spectra above and below $320 \mathrm{~nm}$ deviated only slightly from that of N-acetyl tyrosinamide (27) indicating the virtual absence of tryptophanyl residues. In normal HDL, the tryptophanyl residues, primarily in Apo A-I, contribute more than $90 \%$ of the fluorescence at $320 \mathrm{~nm}$ and $\sim 100 \%$ at $328 \mathrm{~nm}$.

The secondary structure of the protein in agarose fraction III was evaluated by circular dichroism measurements in the far ultraviolet wavelength region. The large negative ellipticities at 208 and 220 $\mathrm{nm}$ indicate that the Apo A-II as a constituent of this Tangier lipoprotein has a high helical content. At 220 $\mathrm{nm}$ the Apo A-II in $\mathrm{HDL}_{\mathrm{TG}}$ (agarose fraction III, Fig. 7) had a mean residue ellipticity of 21,800 , whereas that of lipid-free Apo A-II, at pH 7.4, was 14,500. The former value suggests a helical content of about $75 \%$ for the Tangier Apo A-II in $\mathrm{HDL}_{\mathrm{TG}}$.

The lipid composition of the Tangier Apo A-IIcontaining particle $\left(\mathrm{HDL}_{\mathrm{TG}}\right.$ ) was quite similar to that of normal HDL (Table I). Phosphatidyl choline and SPM were the most abundant phospholipids, and their relative proportions were virtually identical to control HDL. Cholesteryl esters were the major neutral lipids and the quantity of free cholesterol was only slightly higher than normal (Table I). The limited material available did not permit accurate determinations of

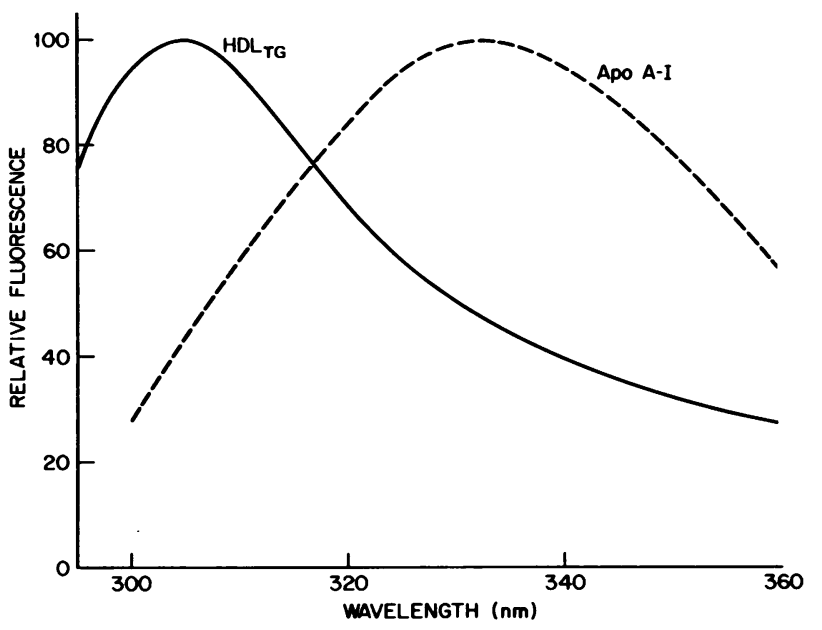

FIGURE 6 Fluorescence spectrum of $\mathrm{HDL}_{\mathrm{TG}}$ at $\mathrm{pH} 8(0.05 \mathrm{M}$ phosphate). The emission spectrum of isolated control Apo A-I is included for comparison. Excitation was at $280 \mathrm{~nm}$.

phosphatidyl ethanolamine, phosphatidyl serine, lysophosphatidyl choline, and triglyceride which are minor lipid constituents of normal HDL.

Comparison of Tangier and control Apo A-II. Tangier Apo A-II from four patients was obtained by chloroform:methanol (2:1) delipidation of agarose fraction III. Apo A-II from a fifth patient (C.N.) was isolated from the delipidated $1.063-1.21-\mathrm{g} / \mathrm{ml}$ density fraction by chromatography on Sephadex G-200 (Pharmacia Fine Chemicals Inc., Piscataway, N. J.)

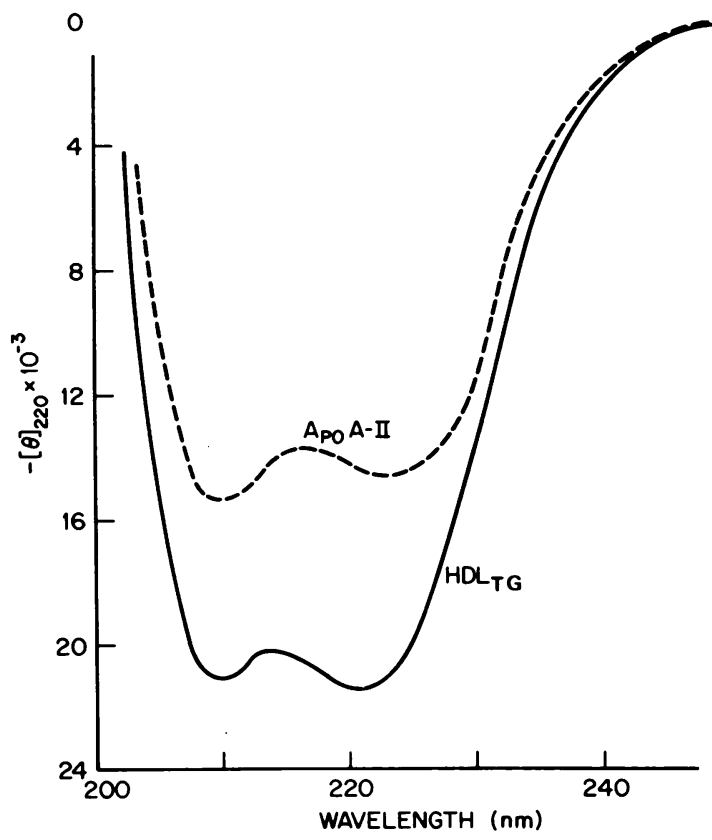

FIGURE 7 The circular dichroic spectra of isolated control Apo A-II and $\mathrm{HDL}_{\mathrm{TG}}$ at $\mathrm{pH} 8$ in $0.05 \mathrm{M}$ phosphate. 
TABLE I

Composition of $H D L_{T G}$

\begin{tabular}{|c|c|c|c|c|}
\hline & \multicolumn{2}{|c|}{$\mathrm{HDL}_{\mathrm{TG}}$} & \multicolumn{2}{|c|}{ Normal HDL* } \\
\hline & P. L. & T. L. & Sample 1 & Sample 2 \\
\hline & \multicolumn{4}{|c|}{$\% d r y w t$} \\
\hline Protein & 53 & 52 & 57 & 57 \\
\hline Phospholipid $\ddagger$ & 23 & 23 & 23 & 24 \\
\hline$P C \S$ & 19 & 19 & 17 & 19 \\
\hline SPM & 4 & 3 & 4 & 4 \\
\hline Cholesteryl-esters & 19 & 20 & 17 & 16 \\
\hline Cholesterol & 5 & 5 & 3 & 3 \\
\hline
\end{tabular}

* Normal HDL samples were prepared by ultracentrifugation $(d=1.063-1.21 \mathrm{~g} / \mathrm{ml})$.

\$ Triglycerides and minor phospholipids were not quantitated and compositions are based only on protein, phospholipid, and free- and ester-cholesterol determinations.

\$ PC, phosphatidyl choline. Minor phospholipids (phosphatidyl serine, phosphatidyl ethanolamine, lysophosphatidyl choline) were not visualized by iodine chamber examination of $\mathrm{HDL}_{\mathrm{TG}}$ lipids. The small differences between total phospholipid and the sum of PC and SPM are accounted for by these or preparative losses.

eluted with $5 \mathrm{M}$ guanidine $\mathrm{HCl}$. The bulk of the protein in Tangier HDL (that was not fractionated by agarose-gel chromatography) eluted in the column void volume (Fig. 8) and was immunochemically identical to Apo B. Albumin was also present in the early eluting fractions and the Apo A-II accounted for a relatively small proportion of the total high density apoprotein.

Amino acid analyses of Tangier and control Apo A-II were similar (Table II) in spite of the different methods used in their preparation. The possibility of structural differences was also approached by treating Tangier and normal Apo A-II with trypsin and then analyzing the peptides generated by polyacrylamide

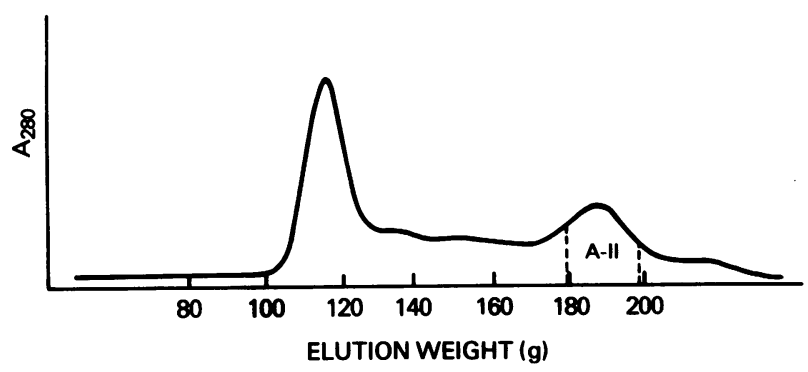

FIGURE 8 Gel chromatography (Sephadex G-200, 5 M guanidine $\mathrm{HCl}, 0.05 \mathrm{M}$ Tris- $\mathrm{HCl}, \mathrm{pH}$ ) of Tangier $\mathrm{HDL}(d$ $=1.063-1.21 \mathrm{~g} / \mathrm{ml} \mathrm{KBr}$ ultracentrifugal fraction). HDL was isolated by ultracentrifugation from Tangier plasma (C.N.), delipidated, and then applied to the column without further purification. Apo A-II was collected as indicated and subjected to amino acid analysis (Table II). gel electróphoresis and one-dimensional thin-layer chromatography (not shown). The chromatographic patterns of tryptic peptides from Tangier and control Apo A-II were almost indistinguishable, although the limited resolution of several of the peptides precludes firm conclusions about the detailed structure of Tangier Apo A-II. Moreover, definite results as to the identity or nonidentity of tryptic peptides cannot be obtained without their isolation and amino acid sequence analyses.

Reassembly of Tangier Apo A-II with SPM. Lipid-protein complexes obtained in vitro by recombination of normal Apo A-II with phosphatidyl choline or SPM have been previously characterized (16, 28-30). When Tangier Apo A-II was recombined with $\left[{ }^{3} \mathrm{H}\right] \mathrm{SPM}$, complexes with a SPM:protein molar ratio of 37:1 were isolated after sequential flotation in the ultracentrifuge (Table III). The control Apo A-II-SPM preparation had a comparable lipid-protein ratio. Similar stoichiometry was observed when ultracentrifugation was followed by agarose-column fractionation of the recombinant particles. Examination by electron microscopy showed that the Tangier Apo A-II particles were discoidal structures similar to those previously described; the Tangier and normal Apo A-II disks were 70-75 $\AA$ wide.

${ }^{125}$ I-VLDL incubation experiments. The distribution of ${ }^{125}$ I radioactivity in the VLDL, low density

TABLE II

Amino Acid Composition of Tangier Apo A-II

\begin{tabular}{lrrrrrr}
\hline \multicolumn{1}{c}{$\begin{array}{c}\text { Amino acid } \\
\text { residues* }\end{array}$} & T. L. & P. L. & C. N. & J. S. & E. G. & $\begin{array}{c}\text { Sequence } \\
\text { analysis } \\
\text { datat }\end{array}$ \\
\hline & \multicolumn{6}{c}{ moles/100 moles amino acid } \\
Aspartic acid & 4.0 & 5.1 & 5.3 & 4.9 & 4.8 & 4.1 \\
Threonine & 7.6 & 7.7 & 6.9 & 7.6 & 7.5 & 7.7 \\
Serine & 7.5 & 7.9 & 7.3 & 7.7 & 7.7 & 7.3 \\
Glutamic acid & 21.7 & 21.3 & 19.6 & 21.2 & 20.4 & 20.5 \\
Glycine & 4.0 & 4.4 & 4.9 & 4.5 & 4.6 & 4.0 \\
Alanine & 6.7 & 7.3 & 6.6 & 6.8 & 6.6 & 6.4 \\
Valine & 6.8 & 7.8 & 7.6 & 7.1 & 7.6 & 7.8 \\
Methionine & 1.2 & 1.2 & 1.1 & 0.9 & 1.1 & 1.1 \\
Isoleucine & 1.0 & 1.2 & 1.7 & 1.2 & 1.3 & 1.2 \\
Leucine & 10.5 & 10.5 & 10.4 & 10.7 & 10.5 & 10.7 \\
Tyrosine & 5.4 & 4.6 & 5.0 & 5.1 & 5.0 & 5.3 \\
Phenylalanine & 5.6 & 5.0 & 5.1 & 5.0 & 5.2 & 5.4 \\
Lysine & 11.9 & 11.1 & 11.1 & 11.3 & 11.7 & 11.8 \\
Proline & 6.2 & 5.3 & 5.6 & 6.0 & 6.0 & 5.7 \\
Histidine & 0.0 & 0.0 & 0.0 & 0.0 & 0.0 & 0.0 \\
Arginine & 0.0 & 0.0 & 0.0 & 0.0 & 0.0 & 0.0 \\
\hline
\end{tabular}

* Asparagine and glutamine are converted to their respective dicarboxylic acids, and tryptophan is destroyed under the conditions of acid hydrolysis used here.

\$ Amino acid composition of normal S-carboxymethylatedApo A-II as determined by Lux et al. $(18,49)$. 
lipoprotein, and HDL density fractions of normal and Tangier plasma after incubation with ${ }^{125}$ I-normolipidemic VLDL is shown in Table IV. In contrast to the radioactivity distribution of normolipidemic plasma, only small amounts of radioactivity were associated with the $d=1.063-1.21 \mathrm{~g} / \mathrm{ml}$ fraction of Tangier plasma.

About $28 \%$ of the radioactivity in the original VLDL was found collectively in the $\mathrm{C}$ apoproteins (Apo C-II, Apo C-III ${ }_{1}$, and Apo C- $\mathrm{III}_{2}$ ). After in vitro incubation of ${ }^{125}$ I-labeled VLDL with normal plasma, 55\% of the radioactivity originally associated with the $\mathrm{C}$ apoproteins in VLDL was transferred to the HDL density region. In Tangier HDL, however, the radioactivity was not confined to the $\mathrm{C}$ apoproteins, but rather to Apo $\mathrm{B}$ or other apoproteins at the interface of stacking and running gel which were present as contaminating fraction.

The failure to detect $\mathrm{C}$ apoproteins as protein constituents of Tangier HDL cannot be explained on the basis of the total absence of these proteins from Tangier plasma, since their presence can be demonstrated by coelectrophoresis of Tangier VLDL apoproteins with normal VLDL apoproteins in urea-polyacrylamide disc gels (not shown).

\section{DISCUSSION}

This study was designed to further clarify the nature of HDL in Tangier disease. We have previously demonstrated by radioimmunoassay determination of $\mathrm{A}$ apoproteins in Tangier plasma, that Apo A-I, the major apoprotein of normal HDL, is almost exclusively confined to the $d>1.21 \mathrm{~g} / \mathrm{ml}$ ultracentrifugal fraction and absent from the $d=1.063-1.21 \mathrm{~g} / \mathrm{ml}$ fraction (3). By contrast, significant amounts of Apo A-II were present in the HDL density fraction of Tangier plasma (3).
TABLE III

Recombination of Apo A-II with $\left[{ }^{3} \mathrm{H}\right] \mathrm{SPM}$

\begin{tabular}{|c|c|c|c|c|c|c|}
\hline & \multicolumn{2}{|c|}{$\begin{array}{l}\text { Recombination } \\
\text { mixture }\end{array}$} & \multicolumn{2}{|c|}{$\begin{array}{c}1.21 \mathrm{~g} / \mathrm{ml} \\
\text { supemate }\end{array}$} & \multicolumn{2}{|c|}{$\begin{array}{c}\text { Lipid to protein } \\
\text { ratio }\end{array}$} \\
\hline & Lipid & Protein & Lipid & Protein & Weight $\S$ & Molar" \\
\hline & \multicolumn{2}{|c|}{$m g$} & \multicolumn{2}{|c|}{$m g$} & & \\
\hline $\begin{array}{l}\text { Apo A-II, } \\
\text { control }\end{array}$ & 1.9 & 0.67 & 1.09 & 0.59 & 1.847 & 35.9 \\
\hline $\begin{array}{l}\text { Apo A-II, } \\
\text { Tangier }\end{array}$ & 1.9 & 0.55 & 0.91 & 0.48 & 1.895 & 36.8 \\
\hline
\end{tabular}

* $1.21 \mathrm{~g} / \mathrm{ml}$ supernate, $2-\mathrm{ml}$ supernatant fraction from the ultracentrifugation of recombined lipid-protein complexes at density $1.25 \mathrm{~g} / \mathrm{ml}$.

\$ The values for protein have been set at one in all cases. $\$$ Calculations were made on the basis of specific activity of SPM and Lowry et al. (17) protein determinations.

"Calculations were made assuming an average molecular weight for SPM $(\mathrm{mol} \mathrm{wt}=850)$ and a molecular weight for Apo A-II of 16,500.

The presence of apoproteins antigenically related to normal HDL was recognized in early studies of Tangier plasma $(31,32)$. The striking pleomorphism of the lipoproteins of density $1.063-1.21 \mathrm{~g} / \mathrm{ml}$ (Fig. 1) was not appreciated, however, and all of the apoproteins normally found in HDL were considered to be associated with Tangier HDL, albeit in abnormal proportions (2).

Fractionation of the $1.063-1.21 \mathrm{~g} / \mathrm{ml}$ lipoproteins by agarose-column chromatography (Fig. 2) demonstrates that only a relatively minor quantity of Tangier "HDL" has alpha mobility (Fig. 3). Morphologically, these alpha-migrating lipoproteins are tiny spherical particles, $55-75 \AA$, overlapping in size only the smallest HDL found in normal plasma (Fig. 4). Their gross

TABLE IV

Transfer of VLDL Radioactivity to Other Lipoproteins after in Vitro Incubation

\begin{tabular}{|c|c|c|c|c|c|c|c|c|}
\hline \multirow[b]{3}{*}{ Density } & \multirow{2}{*}{\multicolumn{2}{|c|}{ Incubated with $0.9 \% \mathrm{NaCl}$}} & \multirow{2}{*}{\multicolumn{2}{|c|}{$\begin{array}{l}\text { Incubated with } \\
\text { normal plasma }\end{array}$}} & \multicolumn{4}{|c|}{ Incubated with Tangier plasma } \\
\hline & & & & & \multicolumn{2}{|c|}{ E. G. } & \multicolumn{2}{|c|}{ J. S. } \\
\hline & $\mathrm{A}^{*}$ & $\mathrm{~B} \ddagger$ & $\mathrm{A}^{*}$ & Bt & $\mathrm{A}^{*}$ & Bł & $\mathrm{A}^{*}$ & $\mathrm{~B} !$ \\
\hline \multicolumn{9}{|l|}{$\mathrm{g} / \mathrm{ml} \mathrm{KBr}$} \\
\hline 1.006 & 96.5 & 10.3 & 61.7 & 9.6 & 77.8 & 10.7 & 79.6 & 12.0 \\
\hline $1.006-1.063$ & 2.5 & 18.4 & 9.7 & 22.0 & 17.1 & 14.0 & 14.6 & 10.9 \\
\hline $1.063-1.21$ & Trace & - & 24.5 & 10.4 & 1.5 & 12.1 & 0.9 & 14.4 \\
\hline 1.21 & Trace & - & 4.1 & - & 3.6 & - & 2.9 & - \\
\hline
\end{tabular}

* Percent distribution of radioactivity.

\$ Lipid-bound ${ }^{125}$ I (percent).

${ }^{125} \mathrm{I}$-labeled VLDL were incubated for $60 \mathrm{~min}$ at $37^{\circ} \mathrm{C}$ with either $0.9 \% \mathrm{NaCl}$, normal plasma, or Tangier plasma. Distribution of radioactivity in lipoproteins and lipoprotein lipids was determined as described in Methods. 
chemical composition is remarkably similar to control HDL (Table I), but by a variety of criteria their apoprotein content is very different. Apo A-I and the C apoproteins are nearly or completely absent.

Apo A-II, which usually comprises $30-35 \%$ of Apo HDL, was the only apoprotein consistently demonstrated in the isolated alpha-migrating lipoprotein from Tangier HDL. Apo A-II was readily demonstrable in this lipoprotein by SDS gel electrophoresis (Fig. 5) and immunodiffusion. The amino acid composition of Tangier Apo A-II, obtained by simple delipidation of agarose fraction III without any subsequent attempts of purification (Table II), closely approximates that determined from primary sequence analysis. The Tangier Apo A-II recovered from G-200 guanidine HCl chromatography of whole Tangier Apo HDL (C.N., Table II) deviated more from the known composition.

The proteins in native HDL appear to contain a high content of alpha helix which is partially lost when the lipoprotein lipid is removed by organic solvent extraction $(33,34)$. Studies of the Apo A-IIcontaining particles isolated from Tangier plasma have afforded a unique opportunity to determine the secondary structure of Apo A-II in a natural, though possibly abnormal lipoprotein. The Apo A-II as a constituent of this Tangier lipoprotein contains about $75 \%$ alpha helix (Fig. 7), whereas lipid-free Apo A-II contains only $35-45 \%$ alpha helix as judged by circular dichroic spectra $(16,28,35)$. Reassembly of Apo A-II with lipids in vitro can increase the alpha-helix content to $60-65 \%(16,28)$ and the value of $75 \%$ in the Tangier Apo A-II particle approximates that estimated for the protein in native HDL (36).

The Apo A-II isolated from Tangier HDL appears to recombine normally with SPM to form discoidal lipoprotein particles. Moreover, the major peptides released on tryptic digestion of Tangier and control Apo A-II are indistinguishable. These findings mitigate against the possibility that a structurally abnormal Apo A-II is elaborated in Tangier disease but the question will not be completely resolved until the amino acid sequence of Tangier Apo A-II is determined.

Of particular interest was the finding that besides Apo A-I, the $\mathrm{C}$ apoproteins were also absent from the Tangier Apo A-II particle. It must be concluded that the Apo A-II particle in Tangier plasma is incapable of integrating $\mathrm{C}$ apoproteins into its structure and it appears that the $\mathrm{C}$ apoproteins do not form independent HDL unassociated with the normal proteins and lipids of this density class. The transfer and exchange of $\mathrm{C}$ apoproteins from HDL to VLDL, and vice versa, has been previously recognized as a physiological mechanism in the catabolism of triglyceride-rich lipoproteins (37). The impairment of this mechanism might explain the hypertriglyceridemia and fasting chylomicronemia observed in patients with Tangier disease.
Unliked discoidal HDL observed in lecithin-cholesterol acyltransferase deficiency (38-41), in cholestasis in man (42-44), in cholesterol-fed guinea pigs $(45,46)$, and in rat liver perfusates (47), Tangier HDL particles are of spherical, pseudomicellar shape containing a substantial amount of cholesteryl esters. Previous studies have suggested an essential role for lecithincholesterol acyltransferase (LCAT) in the generation of pseudomicellar particles of plasma HDL as well as for Apo A-I as a cofactor in the LCAT reaction (47, 48). Apparently, the small amounts of Apo A-I in Tangier plasma $(<1 \mathrm{mg} / \mathrm{dl})$ are sufficient to maintain the conversion of cholesterol and lecithin to cholesteryl esters and lysolecithin, and LCAT activity is present in spite of the absence of normal HDL. This could also be confirmed by in vitro measurements of LCAT in Tangier plasma. ${ }^{2}$

We have no experimental data bearing on the origin of the Apo A-II-containing lipoprotein particles in Tangier plasma. They may be products of a mutant gene coding an abnormal lipoprotein form. They may reflect the failure of a structurally abnormal Apo A-I to associate with normal HDL particles. On the other hand, they may represent a normal secretory HDL subpopulation, or a normal HDL degradation product whose presence is masked in normal plasma by an overwhelming amount of other HDL.

\section{ACKNOWLEDGMENTS}

We wish to thank Mrs. Anne Houser, Ms. Elanne Smootz, Ms. Marianne Nyfeller, and Mr. Robert Heinen for excellent technical assistance.

\section{REFERENCES}

1. Fredrickson, D. S., A. M. Gotto, and R. I. Levy. 1972. Familial lipoprotein deficiency (Abetalipoproteinemia, hypobetalipoproteinemia, and Tangier disease). In The Metabolic Basis of Inherited Disease. J. B. Stanbury, J. B. Wyngaarden, and D. S. Fredrickson, editors. McGraw-Hill Book Company, New York. 3rd edition. 493-530.

2. Lux, S. E., R. I. Levy, A. M. Gotto, and D. S. Fredrickson. 1972. Studies on the protein defect in Tangier disease. Isolation and characterization of an abnormal high density lipoprotein. J. Clin. Invest. 51: 2505-2519.

3. Assmann, G., E. Smootz, K. Adler, A. Capurso, and K. Oette. 1977. The lipoprotein abnormality in Tangier disease. Quantitation of A apoproteins. J. Clin. Invest. 59: 565-575.

4. Fredrickson, D. S., P. H. Altrocchi, L. V. Avioli, D. S. Goodman, and H. C. Goodman. 1961. Tangier disease. Ann. Intern. Med. 55: 1016-1031.

5. Fredrickson, D. S. 1964. The inheritance of high density lipoprotein deficiency (Tangier disease). J. Clin. Invest. 43: 228-236.

${ }^{2}$ Assmann, G., G. Schmitz, and H. Heckers. Unpublished observations. 
6. Waldorf, D. S., R. I. Levy, and D. S. Fredrickson. 1967. Cutaneous cholesteryl ester deposition in Tangier disease. Arch. Dermatol. 95: 161-165.

7. Ferrans, V. J., and D. S. Frederickson. 1975. The pathology of Tangier disease. A light and electron microscopic study. Am. J. Pathol. 78: 101-158.

8. Gheorghiu, Th., G. Assmann, and H. E. Schaefer. 1976. Endoscopic findings in Tangier Disease. Endoscopy. 8: 164-169.

9. Masket, B. H., R. I. Levy, and D. S. Fredrickson. 1973. The use of polyacrylamide gel electrophoresis in differentiating type III hyperlipoproteinemia. J. Lab. Clin. Med. 81: 794-802.

10. Reisfeld, R. A., and P. A. Small, Jr. 1966. Electrophoretic heterogeneity of polypeptide chains of specific antibodies. Science (Wash. D. C.). 152: 1253-1255.

11. Weber, K., and M. Osborn. 1969. The reliability of molecular weight determinations by dodecyl sulfatepolyacrylamide gel electrophoresis. J. Biol. Chem. 244: 4406-4412.

12. Scanu, A., J. Toth, C. Edelstein, S. Koga, and E. Stiller. 1969. Fractionation of human serum high density lipoproteins in urea solutions. Evidence for polypeptide heterogeneity. Biochemistry. 8: 3309-3316.

13. McFarlane, A. S. 1958. Efficient trace-labelling of proteins with iodine. Nature (Lond.). 182: 53.

14. Bilheimer, D. W., S. Eisenberg, and R. I. Levy. 1972. The metabolism of very low density lipoproteins. I. Preliminary in vitro and in vivo observations. Biochim. Biophys. Acta. 260: 212-221.

15. Stoffel, W., D. LeKim, and T. S. Tschung. 1971. A simple chemical method for labelling phosphatidylcholine and sphingomyelin in the choline moiety. HoppeSeyler's Z. Physiol. Chem. 352: 1058-1064.

16. Assmann, G., and H. B. Brewer, Jr. 1974. Lipid-protein interactions in high density lipoproteins. Proc. Natl. Acad. Sci. U. S. A. 71: 989-993.

17. Lowry, O. H., N. J. Rosebrough, A. L. Farr, and R. J. Randall. 1951. Protein measurement with the Folin phenol reagent. J. Biol. Chem. 193: 265-275.

18. Lux, S. E., K. M. John, R. Ronan, and H. B. Brewer, Jr. 1972. Isolation and characterization of the tryptic and cyanogen bromide peptides of apoLp-Gln-II (apoAII), a plasma high density apolipoprotein. J. Biol. Chem. 247: 7519-7527.

19. Greenfield, N., and G. D. Fasman. 1969. Computed circular dichroism spectra for the evaluation of protein conformation. Biochemistry. 8: 4108-4116.

20. Gwynne, J., H. Brewer, Jr., and H. Edelhoch. 1974. The molecular properties of apo A-I from human high density lipoprotein. J. Biol. Chem. 249: 2411-2416.

21. Keutman, H. T., and J. T. Potts, Jr. 1969. Improved recovery of methionine after acid hydrolysis using mercaptoethanol. Anal. Biochem. 29: 175-185.

22. Moore, S., D. H. Spackman, and W. H. Stein. 1958. Chromatography of amino acids on sulfonated polystyrene resins. An improved system. Anal. Chem. 30: 1185-1190.

23. Hubbard, R. W. 1965. Studies in accelerated amino acid analysis. Biochem. Biophys. Res. Commun. 19: 679685.

24. Itaya, K., and M. Ui. 1966. A new micromethod for the colorimetric determination of inorganic phosphate. Clin. Chim. Acta. 14: 361-366.

25. Chalvardjian, A., and E. Rudnicki. 1970. Determination of lipid phosphorus in the nanomolar range. Anal. Biochem. 36: 225-226.
26. Zak, B., R. C. Dickenman, E. G. White, H. Burnett, and P. J. Cherney. 1954. Rapid estimation of free and total cholesterol. Am. J. Clin. Pathol. 24: 1307-1315.

27. Bernstein, R. S., M. Wilchek, and H. Edelhoch. 1969. Structural studies on polypeptide hormones. II. Polarization of fluorescence. J. Biol. Chem. 244: 4398-4405.

28. Lux, S. E., K. M. John, S. Fleischer, R. L. Jackson, and A. M. Gotto, Jr. 1972. Identification of the lipidbinding cyanogen bromide fragment from the cystinecontaining high density apolipoprotein, apoLP-gln-II. Biochem. Biophys. Res. Commun. 49: 23-29.

29. Jackson, R. L., J. D. Morrisett, H. J. Pownall, and A. M. Gotto, Jr. 1973. Human high density lipoprotein, apolipoprotein glutamine II. The immunochemical and lipidbinding properties of apolipoprotein glutamine II derivatives. J. Biol. Chem. 248: 5218-5224.

30. Stoffel, W., O. Zierenberg, B. Tunggal, and E. Schreiber. 1974. ${ }^{13} \mathrm{C}$ nuclear magnetic resonance spectroscopic evidence for hydrophobic lipid-protein interactions in human high density lipoproteins. Proc. Natl. Acad. Sci. U. S. A. 71: 3696-3700.

31. Levy, R. K., and D. S. Fredrickson. 1966. Nature of the alpha lipoproteins in Tangier disease. Circulation. 34 Suppl. III): 156-157. (Abstr.)

32. Hoffman, H. N., and D. S. Fredrickson. 1965. Tangier disease (familial high density lipoprotein deficiency). Clinical and genetic features in two adults. Am. J. Med. 39: 582-593.

33. Scanu, A., and R. Hirz. 1968. On the structure of human serum high-density lipoprotein: studies by the technique of circular dichroism. Proc. Natl. Acad. Sci. U. S. A. 59: 890-894.

34. Gotto, A. M., and B. Shore. 1969. Conformation of human serum high density lipoprotein and its peptide components. Nature (Lond.). 224: 69-70.

35. Scanu, A. M. 1970. The effect of reduction and carboxymethylation on the circular dichroic spectra of two polypeptide classes on serum high density lipoprotein. Biochim. Biophys. Acta. 200: 570-572.

36. Scanu, A. 1965. Studies on the conformation of human serum high-density lipoproteins $\mathrm{HDL}_{2}$ and $\mathrm{HDL}_{3}$. Proc. Natl. Acad. Sci. U. S. A. 54: 1699-1705.

37. Havel, R. J., J. P. Kane, and M. L. Kashyap). 1973. Interchange of apolipoproteins between chylomicrons and high density lipoproteins during alimentary lipemia in man. J. Clin. Invest. 52: 32-38.

38. Glomset, J. A., and K. R. Norum. 1973. The metabolic role of lecithin: cholesterol acyltransferase: perspectives from pathology. Adv. Lipid Res. 11: 1-65.

39. Norum, K. R., J. A. Glomset, A. V. Nichols, T. Forte, J. J. Albers, W. C. King, C. D. Mitchell, K. R. Applegate, E. L. Gong, V. Cabana, and E. Gjone. 1975. Plasma lipoproteins in familial lecithin: cholesterol acyltransferase deficiency: effects of incubation with lecithin: cholesterol acyltransferase in vitro. Scand. J. Clin. Lab. Invest. Suppl. 142: 31-55.

40. Utermann, G., H. J. Menzel, and K. H. Langer. 1974. On the polypeptide composition of an abnormal high density lipoprotein (LP-E) occurring in LCAT-deficient plasma. FEBS (Fed. Eur. Biochem. Soc.) Lett. 45: 2932.

41. Uterman, G., H. J. Menzel, K. H. Langer, and P. Dieker. 1975. Lipoproteins in lecithin-cholesterol-acyltransferase-(LCAT)-deficiency. II. Further studies on the abnormal high-density-lipoproteins. Humangenetik. 27: 185-187.

42. Hamilton, R. L., R. J. Havel, and M. C. Williams. 1974. 
Lipid bilayer structure of plasma lipoproteins in cholestasis. Fed. Proc. 33: 351. (Abstr.)

43. Blomhoff, J. 1974. High density lipoproteins in cholestasis. Scand. J. Gastroenterol. 9: 591-596.

44. Danielsson, B., R. Ekman, and B-G. Petersson. 1975. An abnormal high density lipoprotein in cholestatic plasma isolated by zonal ultracentrifugation. FEBS (Fed. Eur. Biochem. Soc.) Lett. 50: 180-184.

45. Sardet, C., H. Hansma, and R. Ostwald. 1972. Characterization of guinea pig plasma lipoproteins: the appearance of new lipoproteins in response to dietary cholesterol. J. Lipid Res. 13: 624-639.

46. Ostwald, R., and L. S. S. Guo. 1975. Changes in the high density (HDL)-apoproteins of guinea pigs (GP) in response to dietary cholesterol (C). Fed. Proc. 34: 499. (Abstr.)

47. Hamilton, R. L., M. C. Williams, C. J. Fielding, and R. J. Havel. 1976. Discoidal Bilayer Structure of nascent high density lipoproteins from perfused rat liver. J. Clin. Invest. 58: 667-680.

48. Fielding, C. J., V. G. Shore, and P. E. Fielding. 1972. A protein cofactor of lecithin:cholesterol acyltransferase. Biochem. Biophys. Res. Commun. 46: 1493-1498.

49. Lux, S. E., K. M. John, and H. B. Brewer, Jr., 1972. Isolation and characterization of ApoLp-Gln-II (ApoA-II), a plasma high density apolipoprotein, containing two identical polypeptide chains. J. Biol. Chem. 247: 75107518 . 